\title{
SARS-COV-2 IS A BIOLOGICAL WARFARE WEAPON
}

\author{
Francis A. BOYLE22 \\ University of Illinois College of Law
}

\begin{abstract}
The article deals with the theoretical and practical assumptions, based on available facts and research related to COVID-19, in order to discern the origin of the coronavirus and its consequences on national and international security. The main finding is that the world is faced with an extremely dangerous biowarfare weapon, i.e. that the virus has been engineered in lab conditions. The acknowledgement of this fact may be of utmost importance for seeking solutions and adequate responses. The analysis shows that great world powers invest enormous amounts of money into further developments of biological weapons, and the academia plays significant role in the endeavor. In addition to human costs, what is at stake here are human rights, democracy and the security of mankind.
\end{abstract}

Keywords: coronavirus, weaponization, nanotechnology, engineering, biowarfare.

\section{The Origin of SARS-CoV-2}

The literature review shows that one of the primary investigators on the 2015 paper from the University of North Carolina - "A SARS-like Cluster of Circulating Bat Coronaviruses Shows Potential for Human Emergence" (Menachery 2015) - was Dr. Shi Zhengli, a virologist who in 2010 had published a paper discussing the weaponization of the SARS virus (Hou 2010). Normally, while the coronavirus found in bats may be the basis for SARS (Zeng 2016), it typically does not infect humans as it does not target the ACE- 2 receptor. The infectious agent causing the current pandemic is called SARS-CoV-2 - SARS standing for "severe acute respiratory syndrome" and CoV2 indicating that it is a second type of SARS coronavirus known to infect humans. SARS-CoV-2, of course, contains the genetic modification to attach to ACE2 receptors in human cells, which allows it to infect them. Zhengli's publications show that she engineered this bat coronavirus into one that crosses species and infects humans. She has in fact been working on this for more than 10 years. In addition, an Indian article (Pradhan 2020) that ended up being withdrawn due to intense political pressure, shows that a specific envelope protein from the HIV virus called GP41 was integrated in the RNA sequences of SARS-CoV-2. In other words, the implication is that the HIV virus was genetically engineered into SARS.

In summary, SARS-CoV-2 appears to be a bioengineered bat coronavirus (Zhou 2020). Zhengli then genetically modified the virus to integrate spike proteins that allows the virus to enter human

22 Contact address: fboyle@illinois.edu. 
cells by attaching to ACE-2 receptors. That was the first modification. The second modification was to integrate an envelope protein from HIV called GP141, which tends to impair the immune system. A third modification appears to involve nanotechnology to make the virus light enough to remain airborne for a long time, apparently giving it a range of up to 27 feet (Bourouiba 2020).

While the BSL-4 lab in Wuhan may have leaked the virus, its creation does not appear to be limited to the Chinese. Namely, the chairman of the Harvard department of chemistry, nanoscience expert Dr. Charles Lieber, was arrested by U.S. federal agencies, suspected of illegal dealings with China (The Economist 2020). Lieber has denied the allegations. The Wuhan University of Technology (WUT) allegedly paid him $\$ 50,000$ a month from 2012 to 2017 to help establish and oversee the WUT-Harvard Joint Nano Key Laboratory. He also received another $\$ 150,000$ a month in living expenses from China's Thousand Talents program. The problem was, Harvard officials claim they had not approved the lab and didn't know about it until 2015. The cover story here - that Harvard did not know what was going on - is preposterous. According to my personal experience (seven years at Harvard, three degrees and two years teaching at Harvard) this is hard to believe. Of course, Harvard knew that its chair of the chemistry department had the lab in Wuhan, China, where he was working on nanotechnology with respect to chemical and biological materials. That was reported. They did not disclose what the materials were. In addition, it has been reported that Harvard was a cooperating institution with the Wuhan BSL-4.

The first reported case of COVID-19 infection was around or about November 16, 2019. Depending on the incubation period, which is still unknown, the initial leak might have occurred anywhere near the beginning of November 2019. The official estimate is a 14-day incubation period, but a British health expert believes it is 24 days, and North Korean biological warfare experts believe it is 30 days. Wuhan and Hubei Province were basically under martial law. The statements by President $\mathrm{Xi}$ and his assistants made it very clear they were at war here, and that is correct. They were at war with their own biological warfare agent. President Xi fired the party apparatchiks in charge and has brought in trusted military personnel to handle the crisis, as well as large numbers of military forces saying they were health care workers. They hardly looked like ones to any observer. So, that was the best reading of the situation there.

With regard to rumors the COVID-19 virus might have been stolen from a high-security laboratory in Winnipeg, Canada, one could say it might have been the case. Clearly, they had already been working on that at the Wuhan BSL-4 facility. It is confirmed that Dr. Yoshihiro Kawaoka at the University of Wisconsin resurrected the Spanish flu virus for the Pentagon, obviously for weapons purposes, and he specializes in mating the flu virus to all sorts of hideous biowarfare instrumentalities. And there was also a record of him shipping his products to Winnipeg. Winnipeg is Canada's equivalent of Fort Detrick in the US. It is a BSL-4 facility, and they indeed research, develop test, manufacture and stockpile every type of hideous biological warfare weapon that we know of. So, some of this technology could have been stolen from Winnipeg. One could hardly be sure about that but, as already said, the Wuhan BSL-4 had already been working on this to begin with. China had already developed SARS, which had leaked out two to three times before this elsewhere. It seems they were turbocharging SARS, which is what COVID-19 looks to be. This is 
a brand-new generation of biowarfare weapons we have not seen before. Its lethality goes from $15 \%$, as estimated by Lancet, up to $17 \%$ by a British health official and even Chinese statistics. Its infectivity is $83 \%$. It can infect maybe three to four people for every person infected. It has gain of function properties. There are reports that even contaminated human feces give it off, that the human feces radiate off maybe 6 or 7 feet. So, we have never seen anything like this before in the history of biological warfare, at least in the public record.

\section{Understanding the COVID-19 Virus}

The COVID-19 virus is a chimera, like the avian flu virus before it. It includes SARS, an already weaponized coronavirus, along with HIV genetic material. That was in a published article by Indian scientists. One could see the pictures, but political pressure was brought to bear upon them so they withdrew the paper. This is why some scientists are now looking into using HIV drugs to treat it (Advisory Board, 2020). "Novel coronavirus" means it is a new virus not previously known to infect humans. The currently held conventional view is that SARS-CoV-2 was transmitted through animals (zoonotic transmission), specifically bats. This notion is hardly a credible one. While a widely-cited paper (Peng Zhou, Xing-Lou Yang, [...]Zheng-Li Shi 2020) claims to establish that SARS-CoV-2 is a coronavirus of bat origin that then jumped species, the work of one of the authors of that paper, Shi Zhengli, actually involved the weaponization of the SARS virus. (Another Nature paper published that same day reiterates the idea that the COVID-19 pandemic is zoonotically transmitted (Wu et al., 2020). However, other scientific literature establishes that this is indeed an engineered synthetic virus that was not transmitted from animals to humans without human intervention. For starters, a Lancet paper published February 15 (Huang et el., 2020), by physicians who treated some of the first COVID-19 patients in China showed that patient zero, the one believed to have started the transmission, was nowhere near the Wuhan seafood market. What's more, there were no bats sold in or even close to the market. At least one-third of the patients reviewed also had no exposure or links to that market. This data supports the counter-hypothesis that SARS-CoV-2 was not zoonotically transmitted but is in fact an engineered virus. Even U.S. politicians and intelligence agencies have said they believe the virus leaked from the Wuhan BSL-4 lab (Fox News, 14 April 2020). Going through the scientific article that argues that the Australian health board working with Wuhan genetically engineered HIV into SARS also proves that these assumptions are all verified in scientific papers. In addition, it seems that they took that back to the Wuhan BSL-4 and applied nanotechnology to it. The size of molecules indicates that we are dealing with nanotechnology, which is something one does in a BSL-4. Biological weapons nanotechnology is very dangerous, so people working with it have to wear a moon suit with portable air. We also know that one of the cooperating institutions to Wuhan BSL-4 was Harvard. Based on the available literature, one could guess that they tried to weaponize all that together, and that is SARS-CoV-2 that we are dealing with now. In other words, it is SARS, which is genetically engineered biowarfare agent to begin with. Second, it has gain-of-function properties, which makes it more lethal, more infectious. It has HIV in there. That 
was confirmed by the Indian scientists. And the MIT scientist who did a study found it traveled 27 feet through the air.

One could hardly argue that China deliberately released it, shooting itself in the foot. But it was clear they were developing an extremely dangerous unknown biological weapon that had never been seen before, and it leaked out of the lab. As one could see in the Washington Post (14 April, 2020), U.S. State Department officials reported back to Washington that there were inadequate safety precautions and procedures in that lab, to begin with. We also know that SARS has leaked out of other Chinese biological warfare labs. Until the US political leaders come clean with the people, both at the White House and in Congress and state governments, and publicly admit that this is an extremely dangerous offensive biological warfare weapon that we are dealing with, it is hard to see how we shall be able to confront it and stop it, let alone defeat it.

The University of North Carolina's work was existentially dangerous and they knew it all the time. The UNC scientific article co-written by the Wuhan BSL-4 scientist Zhengli (Menachery 2015) says "experiments with the full-length and chimeric SHC014 recombinant viruses were initiated and performed before GOF research funding pause and have since been reviewed and approved for continued study by the NIH." In other words, they admit it was gain-of-function research. It was paused by NIH (National Institutes of Health) (2014). The reason for that was because there was a letter put out by large number of life scientists at the time saying this type of gain-of-function work could be existentially dangerous if it got out in the public. Thus, it had to be terminated. But at the beginning it was NIH who funded the project. Disturbingly, while the NIH halted funding of this kind of gain-of-function research on lethal pathogens in 2014, it reauthorized it in December 2017 (NIH 2019). Given his prior involvement in NIH projects, one could assume that Dr. Yoshihiro Kawaoka's work may have been restarted as well, although there is not a proof of it yet. Kawaoka, from the University of Wisconsin, had resurrected the Spanish flu virus for the Pentagon (Devitt 2008).

Four French scientists published an article in the journal Science Direct on antiviral research on 10 February 2020. They did a genetic analysis of the COVID-19 and it showed a form of bio-weaponization that "may provide a gain of function to the COVID-19 for efficient spreading in human population as compared to other coronaviruses". The phrase "gain of function" means "man-made and weaponized."

\section{COVID-19 - A Weaponized Coronavirus}

As a result of my decades long antibiological warfare work, which goes back to the early days of the Reagan administration - a time in which they were using DNA genetic engineering to manufacture biological weapons -- mysterious outbreaks of disease in both humans and animals around the world that have appeared since then have been the focus of my careful observation. My work drafting the U.S. Biological Weapons Anti-Terrorism Act of 1989 was specifically designed to not only deal with regular biological weapons but also with DNA genetic engineering for biological weapons that was just coming into its infancy when the Biological Weapons Convention was being drafted. Even though the BWC would cover DNA genetic engineering, I wanted to make it clear 
by name that it was covered. I also made it clear that it covered synthetic biology as well. So, when these unexplained mysterious illnesses broke out in early 2020, I monitored them carefully. They could not be explained by normal reasons, such as lack of sanitation, poverty, things of that nature. In Wuhan it seemed pretty suspicious, as there is Biosafety Level 4 facility. It is the first one of the type in China, and it was specifically set up to deal in part with the coronavirus and SARS. The Wuhan BSL-4 is China's First Fort Detrick. Basically, SARS is a weaponized version of the coronavirus. There have been leaks before of SARS out of Chinese biowarfare facilities. Indeed, the only reason for these BSL-4 facilities, based on my experience, is the research, development, testing and stockpiling of offensive biological weapons. For that reason, I stated my opinion on January 24, 2020 that this Wuhan coronavirus leaked out of that BSL-4 facility and that the Chinese government has been lying about it and covering up ever since the beginning of the leak.

\section{Despite Laws, Biowarfare Experimentation is Alive and Well}

As noted, the Wuhan lab is a designated WHO research lab, which may sound perverse, considering these facilities specialize in developing and researching dangerous pathogens that can easily be turned into bioweapons. However, we should not be surprised, as WHO is up to its eyeballs in this type of work and has been for quite some time. The U.S. Centers for Disease Control and Prevention $(C D C)$ and the drug industry also appear to have had their hand in many of the outbreaks of what appear to be weaponized viruses.

At this point, it is not necessary to go through the long history of big pharma getting involved in these affairs. There are huge amounts of money here. I believe the West African Ebola pandemic originated out of the US BSL-4 facility in Sierra Leone, and that they were testing out an experimental so-called vaccine that contained live Ebola and gave it to these poor people, killing about 12,000 of them. As for the CDC, it has been involved in every type of biological warfare death science one could possibly imagine. It is a matter of public record that during the Reagan administration, the CDC and the American Type Culture Collection sent 40 shipments of weapons-grade biological warfare agents to Saddam Hussein in Iraq, in the hope and expectation that he would weaponize these agents and use them against Iran. Of course, the problem is that when that war was over, an order was given to U.S. military forces to blow up Saddam Hussein's biological warfare facilities, and that is not how you deal with biological warfare weapons. It contaminated US troops, and that was a causative factor in the Gulf War Syndrome that murdered about 11,000 U.S. troops and disabled about 100,000 . The U.S. government spent $\$ 100$ billion on biological warfare programs since September 11, 2011 up until October 2015. To put it into perspective, the U.S. spent $\$ 40$ billion (assuming a constant dollar value) on the Manhattan Project, which developed the atomic bomb. Like the Manhattan Project, this is a U.S. offensive biowarfare industry at work today.

Also, the U.S. has some 13,000 death scientists working within the biowarfare industry. Clearly, the Reagan administration, under the influence of its neoconservatives who definitely believe in biological weapons and ethnic-specific biological weapons (you can see that in the PNAC report), were engaged in the use of DNA genetic engineering for the purpose of manufacturing biological 
weapons. That is why I gave a Congressional briefing in Washington, D.C. in 1985. I was asked to do that by the Council for Responsible Genetics that I worked with, which involved some of the leading life scientists in the world, including from MIT and Harvard. I spent seven years at Harvard. I have three degrees and I knew these people. They asked me to serve as their Counsel and give this Congressional briefing. I blew the whistle, and then they asked me to draft the U.S. domestic implementing legislation for the Biological Weapons Convention, which I did. Professor Jonathan King wrote the foreword to my book Biological Warfare and Terrorism (2005). In other words, the leading MIT professor of molecular biology supported what I was arguing in it.

\section{Pandemics Repeatedly Used to Further Police State}

Pandemics have been used to chip away public freedoms. For example, the anthrax scare of 2001 was used as the impetus for signing the Patriot Act, which was the first step in taking away many of our personal freedoms and rolling out a complete surveillance state. For instance, they used Amerithrax to ram the Patriot Act through. The US became a police state. And as I pointed out in Biowarfare and Terrorism (2005), I think the same people who were behind the $9 / 11$ terrorist attack were also behind the Amerithrax, but I am just connecting dots there. Amerithrax came out of a U.S. government biological warfare weapons lab and program. I publicly blew the whistle on that the first weekend of November 2001. The Council for Responsible Genetics was having its convention at Harvard Divinity School and I was chairing a panel with Professor King and other experts on biological warfare and on U.S. biological warfare programs.

As I was walking into the Harvard Divinity School, Fox TV had a camera crew there and I said: Obviously, this came out a U.S. biological weapons program and lab. I conducted the session and made the same comment there. Then I made a comment to a Washington, D.C., radio station to that effect and then to the BBC, so everyone in the world heard me. At that point, someone gave an order that I was never to be interviewed again by any mainstream news about biological warfare programs.

George Orwell's book 1984 has become reality. Ever since I have lectured lawyers at DePaul Law School in Chicago about the totalitarian nature of the Patriot Act. Snowden has correctly pointed out the federal government is spying on everything we say, all of our electronic communications. And again, the proof is I have been completely blackballed out of U.S. media.

\section{Bioweapons Are Developed To Be Used}

As noted, the U.S. government has a large stockpile of Amerithrax - a super weapons-grade nanotechnology anthrax with 1 trillion spores per gram - and that is just the tip of the iceberg of the biological weapons developed. What is more, there is no doubt these weapons will eventually be put to use, as they have been in the past. There was a tabletop exercise (which is a euphemism for a war game) at John Hopkins University in fall 2019 on coronavirus (Center for Health Security 2019). Their estimate was that it killed 65 million people (Bendix 2019). John Hopkins has a BSL-3 facility and they proudly announce it on their website, with justification that they work on developing vaccines. The U.S. government goes out around the world, and this is a matter of 
public record, and scour for every type of hideous disease, fungus, virus and bacteria one can possibly imagine. They then bring it back to these BSL-4 and BSL-3 labs and develop an offensive, biological agent using DNA genetic engineering and synthetic biology, which was originally set up by the Pentagon under DARPA. Once they have this offensive agent, they then proceed to develop a vaccine, because the agent is no good unless you can have a vaccine to protect your own people. In sum, they are developing vaccines to have biological weapons, because a biological weapon consists of two elements: the offensive biological warfare agent in the first place, and then, second, a vaccine to protect your own people, and that is what is being done at all these BSL-4 facilities and these BSL-3s as well. John Hopkins' BSL-3 has dual use. That is what dual use means: they first develop the offensive biological warfare agent and then they develop the supposed vaccine. Indeed, Johns Hopkins University is the biggest recipient of research grants from federal agencies, including the National Institutes of Health, National Science Foundation and Department of Defense. It has also received millions of dollars in research grants from the Gates Foundation (Gates Foundation 2018). In 2016, Johns Hopkins spent more than \$2 billion on research projects, leading all U.S. universities in research spending for the 38th year in a row (Charuchandra 2018).

\section{Can Violations of Biowarfare Treaty Be Enforced?}

As mentioned, I drafted the U.S. domestic implementing legislation for the Biological Weapons Convention. That law is still in force and would provide life imprisonment for everyone involved in the creation and release of SARS-CoV-2. The UNC article says exactly it was dealing with synthetic molecules. In my Biological Weapons Anti-Terrorism Act of 1989, I specifically criminalized - by that name - synthetic molecules. The whole synthetic biology movement was set up and funded by the Pentagon's DARPA. In fact, DARPA money is behind synthetic biology, gene drive and all the rest of it. That is why at the first convention of synthetic biologists, in their final report, one of their key recommendations was the repeal of my Biological Weapons Anti-Terrorism Act - because they fully intended to use synthetic biology to manufacture biological weapons. That is what they have done with Covid-19. The law still applies. It provides for life imprisonment for everyone who has done such a deed, including the scientists involved and everyone who funded this project, knowing it was existentially dangerous. So, just how would we get that process of justice going? There are two ways. First, one should put pressure on the Department of Justice to prosecute the ones involved. It might very difficult to do. Federal statutes require indictments to be brought by U.S. attorneys. If it is impossible to get the U.S. attorney general to sign off on prosecuting these people, then a district attorney, state's attorney, attorney general out there in North Carolina, could indict everyone involved. It is clear from this article (i.e. the 2015 UNC paper) they knew it was gain-of-function, they paused it because it was existentially dangerous, it was then reapproved and they continued it. 


\section{Conclusion: Time to Shutter All BSL-4 and BSL-3 Laboratories}

All BSL-3 and BSL-4 laboratories must be closed down and all biowarfare work with lethal pathogens ceased because they are all existentially dangerous. This is a catastrophe waiting to happen. And it is now happened. Here we are. It is staring us in the face with Covid-19.

Certainly, COVID-19 is nowhere near as devastating as the Black Death or the Spanish Flu Pandemic of 1918 yet, both of which exacted a shocking death toll, all without the aid of synthetic molecules and nanotechnology. The very idea that any of these horrific illnesses might be brought back in turbo-charged form should be terrifying enough for the world to unite in saying "No thanks; we don't want or need that kind of research going on." What value have these dangerous laboratories provided to date compared to the risk they are exposing all of us to? None!

\section{References}

1. Advisory Board (2020), "Can drugs meant for HIV treat the new coronavirus?", 20 February, available at https://www.advisory.com/daily-briefing/2020/02/20/coronavirus-treatment.

2. Bendix Aria (2019), "Health experts issued an ominous warning about a coronavirus pandemic 3 months ago. The virus in their simulation killed 65 million people.", Business Insider, 23 January, available at https://www.businessinsider.com/scientist-simulated-coronavirus-pandemic-deaths-2020-1.

3. Bourouiba Linda (2020), "Turbulent Gas Clouds and Respiratory Pathogen Emissions: Potential Implications for Reducing Transmission of COVID-19", JAMA, 323(18).

4. Boyle A. Francis (2005), Biowarfare and Terrorism, Atlanta: Clarity Press.

5. Chakraborty Barnini (2020), "State Department leaked cables renew theories on origin of coronavirus", Fox News, 14 April, available at https://www.foxnews.com/world/state-department-cables-coronavirus-origin-chinese-lab-bats.

6. Charuchandra Sukanya (2018), "John Hopkins University leads all U.S. universities in research spending for 38th year in a row", John Hopkins University, 23 March, available at https://hub.jhu.edu/2018/03/23/nsf-research-funding-rankings/.

7. Center for Health Security (2019), Event 201 "A Global pandemic exercise", 18 October, available at https://www.centerforhealthsecurity.org/event201/.

8. Devitt Terry (2008), "Scientists isolate genes that made 1918 flu lethal", University of Wisconsin-Madison News, 29 December, available at https://news.wisc.edu/scientistsisolate-genes-that-made-1918-flu-lethal/.

9. Gates Foundation (2018), "Awarded research grants to Johns Hopkins University through 2018", available at https://www.gatesfoundation.org/How-We-Work/Quick-Links/ Grants-Database\#q/k=Johns\%2OHopkins\%20university.

10. Fan Wu et al. (2020), "A new coronavirus associated with human respiratory disease in China, Nature 579, 3 February.

11. Hou Yuxuan et al. (2010), "Angiotensin-converting enzyme 2 (ACE2) proteins of different bat species confer variable susceptibility to SARS-CoV entry", Archives of Virology, 155, 22 June. 
12. Huang Chaolin et el. (2020), "Clinical features of patients infected with 2019 novel coronavirus in Wuhan, China", Lancet, 395(10223), 24 February.

13. Menachery Vineet et al (2020), "A SARS-like cluster of circulating bat coronaviruses shows potential for human emergence", Nat. Med. 21(12), 2015.

14. Pradhan Prashant et al. (2020, "Uncanny similarity of unique inserts in the 2019-nCoV spike protein to HIV-1 gp120 and Gag", bioRhiv, 2 February.

15. National Institutes of Health (NIH) (2014), "Statement on Funding Pause on Certain Types of Gain-of-Function Research", 16 October, available at https://www.nih.gov/about-nih/ who-we-are/nih-director/statements/statement-funding-pause-certain-types-gainfunction-research.

16. National Institutes of Health (NIH) (2017), "NIH Lifts Funding Pause on Gain-of-Function Research", 19 December, available at https://www.nih.gov/about-nih/who-we-are/ nih-director/statements/nih-lifts-funding-pause-gain-function-research.

17. The Economist (2020), "The arrest of Charles Lieber. An American chemist is suspected of illegal dealings with China", 1 February, available at https://www.economist.com/ science-and-technology/2020/02/01/an-american-chemist-is-suspected-of-illegal-dealings-with-china?gclsrc=aw.ds\&gclid=EAlalQobChMI5PGhob3t6AIVxp6zCh32lwBaEAAYASAAEgJaKfD_BwE\&gclsrc=aw.ds.

18. Zhou Peng, Xing-Lou Yang, [...] Zheng-Li Shi (2020), "A pneumonia outbreak associated with a new coronavirus of probable bat origin", Nature 579, 3 February.

19. Zeng Lei-Ping et al. (206), "Bat Severe Acute Respiratory Syndrome-Like Coronavirus WIV1 Encodes an Extra Accessory Protein, ORFX, Involved in Modulation of the Host Immune Response", Journal of Virology, 90 (14). 